\title{
RESEARCH
}

\section{A Multi-Site Qualitative Study Examining Pharmacy Student Perspectives on the Opioid Crisis}

\author{
Maryann Z. Skrabal, PharmD, ${ }^{\mathrm{a}}$ Cynthia Koh-Knox Sharp, PharmD, ${ }^{\mathrm{b}}$ Laura Palombi, PharmD, MPH, ${ }^{\mathrm{c}}$ \\ Amy M. Tiemeier, PharmD, ${ }^{\mathrm{d}}$ Paul C. Walker, PharmD, ${ }^{\mathrm{e}}$ Trish Devine, PharmD, ${ }^{\mathrm{f}}$ Sara A. Spencer, \\ PharmD, ${ }^{\mathrm{g}}$ Kelli L. Coover, PharmD, ${ }^{\mathrm{a}}$ Tran H. Tran, PharmD ${ }^{\mathrm{h}}$ \\ ${ }^{\text {a }}$ Creighton University School of Pharmacy and Health Professions, Omaha, Nebraska \\ ${ }^{\mathrm{b}}$ Purdue University College of Pharmacy, West Lafayette, Indiana \\ ${ }^{\mathrm{c}}$ University of Minnesota College of Pharmacy, Duluth, Minnesota \\ ${ }^{\mathrm{d}}$ St. Louis College of Pharmacy at University of Health Sciences and Pharmacy, St. Louis, Missouri \\ ${ }^{\mathrm{e}}$ University of Michigan College of Pharmacy, Ann Arbor, Michigan \\ ${ }^{\mathrm{f}}$ Butler University College of Pharmacy \& Health Sciences, Indianapolis, Indiana \\ ${ }^{g}$ Binghamton University School of Pharmacy and Pharmaceutical Sciences, Binghamton, New York \\ ${ }^{\mathrm{h}}$ Midwestern University College of Pharmacy, Downers Grove, Illinois \\ Submitted December 17, 2020; accepted April 2, 2021; published August 2021.
}

Objective. To determine pharmacy students' perspectives regarding opioid use, the opioid crisis, and pharmacy education related to both topics.

Methods. Students from each professional year at eight participating schools and colleges of pharmacy were invited to participate in focus groups and answer questions about their experiences with the opioid crisis. Faculty and/or staff moderated the focus groups and audio-recorded responses. Recordings were deidentified, transcribed, and analyzed.

Results. One hundred fifty students participated in one of 29 focus groups conducted. Responses were categorized according to themes using consensual qualitative research (CQR) methodology. Sources impacting student views on the crisis included school, personal and work experience, and media. Perspective changes since starting school included increased knowledge and awareness and decreased bias/stigma.

Conclusion. Conducting focus groups on the opioid crisis provided pharmacy schools with information on what student pharmacists are learning about the crisis, practices they see, and their recommendations to address the crisis. Pharmacy schools can better prepare students to combat the opioid crisis by providing them with training in opioid counseling, use of naloxone, and how to have difficult conversations with patients.

Keywords: opioid, pharmacy, education, experience, student

\section{INTRODUCTION}

The opioid crisis is a public health emergency, complicated by diversion and misuse of prescription opioids and a rise in illicit use of heroin and potent synthetic opioids, such as fentanyl. ${ }^{1}$ This crisis has caused significant morbidity and mortality. Overdoses involving prescription and illicit opioids caused almost 450,000 deaths from 1999, when the opioid crisis was first identified, through $2018 .^{2}$ The number of filled prescriptions peaked in 2012 and decreased thereafter largely due to efforts to

Corresponding Author: Maryann Z. Skrabal, Creighton University, School of Pharmacy and Health Professions, 2500 California Plaza, Omaha, NE 68178. Tel: 402-280-5834. Email: mskrabal@creighton.edu reduce high-dose opioid prescribing. ${ }^{3}$ In 2018, approximately $70 \%$ of the reported 67,367 drug overdose deaths involved any opioid; prescription opioid-involved death rates decreased by $13.5 \%$ from 2017 to 2018 .

Given the widespread use and misuse of opioids, student pharmacists completing internships and experiential training likely encounter patients who use opioids for legitimate as well as illicit purposes. However, the extent of student interactions with these patients, their knowledge of the opioid crisis, and their ability and comfort levels during patient interactions have not been described.

While examples of curricular innovations to improve student education in opioid prevention, intervention, recovery, and harm reduction have been published, there is a paucity of data describing pharmacy student 


\section{American Journal of Pharmaceutical Education 2021; 85 (7) Article 8515.}

perceptions regarding the opioid crisis. This information is critical in determining how pharmacy education must adapt to ensure that the pharmacy workforce is able to contribute to the reversal of the opioid epidemic, or at the very least, ensure that newly trained pharmacists do no harm to patients.

A collaborative task force of American Association of Colleges of Pharmacy (AACP) Experiential Education Section and the Substance Use Disorder Special Interest Group (SUDSIG) members was formed to gather student pharmacists' perspectives about the opioid crisis and opioid use. The purpose of this study was to inform pharmacy educators and practitioners as to how to address the crisis with students and better prepare them for practice.

\section{METHODS}

Students from each professional year from eight schools and colleges of pharmacy were recruited through email and word of mouth to participate in focus groups to discuss their perspectives regarding the opioid crisis. No incentives for participating were offered. Faculty and/or staff moderated the 60- to 90-minute focus groups and audio recorded anonymous responses. Colleges of pharmacy and professional years were deidentified, and recordings were transcribed and analyzed. An institutional review board exemption was obtained at each school.

Participants were first (P1), second (P2), third (P3), and fourth (P4) year student pharmacists from Binghamton University, Butler University, Creighton University, University of Michigan, University of Minnesota-Duluth, Midwestern University-Chicago, Purdue University, and St. Louis College of Pharmacy. The size of focus groups ranged from two to eight participants (mean and median $=$ five; mode $=$ four $)$. Binghamton University did not have $\mathrm{P} 4$ students, so only P1, P2, and P3 students participated. Michigan was only able to recruit P1 students.

Focus group interviews followed a script with interview questions, which consisted of 12 scripted openended and 11 close-ended questions. Sessions were conducted during the fall 2019 semester at each school and audio recorded by each interviewer. All 29 transcripts were transcribed by one research assistant.

Demographic data, including name of school, grade level, previous education, age, gender, and work experience was collected electronically at the beginning of each focus group. Students' written responses to one question were submitted on note cards (physical or electronic) and transcribed for analysis.

Deidentified transcripts were analyzed according to the principles of consensual qualitative research (CQR) methodology. ${ }^{5}$ Eight student coders from two academic institutions were recruited and randomly assigned in pairs to code the transcribed data. At least one student per pair had previous experience with $\mathrm{CQR}$ methodology. Prior to coding, student coders reviewed examples of published qualitative studies using CQR methodology, reviewed the $\mathrm{CQR}$ process, and completed a bias self-check survey. Two faculty auditors met with the student coders and reviewed their progress prior to and during coding to ensure consistent analysis of transcripts and monitored the coders' adherence to the process.

In the first round of the CQR process, the student coders coded data to identify themes mentioned in transcripts and created a master codebook with coding, thematic domains, and subdomains. After the codebook was reviewed by the two faculty auditors and student coders, a second round of CQR was completed and consensus on coding was reached. The codebook was finalized and verified by the student coders and the two faculty auditors. The number of times that domains and subdomains were mentioned in transcripts was tallied and tabulated.

\section{RESULTS}

One hundred fifty students from eight pharmacy schools participated in the focus groups. Demographic data of participants is shown in Table 1. Seven domains (causes, overall impact, stigma, solutions, education, naloxone, sources) and 45 subdomains were identified and coded. Domains, brief descriptions of subdomains, and number of mentions are included in Table 2. Participant responses to quantitative questions are shown by grade level in Table 3.

Ninety-nine percent of participants believed that there is an opioid crisis. Their perspectives were affected by school/curriculum, pharmacy work, media, and personal experiences. The most mentioned causes of the crisis were inappropriate prescribing, lack of awareness, patient issues, the pharmaceutical industry, and pharmacist actions. Thirteen students stated that the overall impact of the crisis was death or overdose. Stigma or bias from the pharmacy community about opioid use was mentioned by 93\% of participants and included judgments based on patient attitudes, public perspectives, patient history, and requests for early fills, needles and syringes as contributors to stigma. Solutions to the crisis included making changes in pharmacy practice and changing or modifying therapies. Student training and patient education were most often mentioned as solutions in the education domain, with $43 \%$ and $31 \%$ of participants giving this response, respectively. One hundred eight (74\%) participants believed naloxone should be dispensed with all opioid prescriptions. Overall, 64\% of participants had been 


\section{American Journal of Pharmaceutical Education 2021; 85 (7) Article 8515.}

Table 1. Demographic Data for Pharmacy Students Participating in a Qualitative Study Examining Perspectives on the Opioid Crisis $(\mathrm{N}=150)^{\mathrm{a}}$

\begin{tabular}{lc}
\hline Student Demographic & N (\%) \\
\hline Grade Level & \\
P1 & $49(32.7)$ \\
P2 & $31(20.7)$ \\
P3 & $36(24)$ \\
P4 & $34(22.7)$ \\
Gender & \\
Female & $105(71)$ \\
Male & $44(29)$ \\
\hline Other & $1(0.6)$ \\
\hline Age (years) & \\
Mean & 23.6 \\
Mode & 20 \\
\hline Range & $19-47$ \\
Past Degree & \\
\hline None & $66(44)$ \\
Associate & $11(7.3)$ \\
\hline Bachelor's & $71(47.3)$ \\
\hline Master's & $6(4)$ \\
\hline Doctorate & $5(3.3)$ \\
\hline Work Experience & \\
\hline Community & $121(80.7)$ \\
\hline Hospital & $45(30)$ \\
\hline Other & $16(10.7)$ \\
\hline
\end{tabular}

a This study recruited first through fourth year Doctor of Pharmacy students from eight US schools and colleges: Binghamton University, Butler University, Creighton University, University of Michigan, University of Minnesota-Duluth, Midwestern University-Chicago, Purdue University, and St. Louis College of Pharmacy. The number and ranking of participants from each school varied.

${ }^{\mathrm{b}}$ Students could indicate more than one prior degree.

${ }^{\mathrm{c}}$ Students could indicate work experience in multiple settings.

trained in how to use naloxone; however, only $33 \%$ of P1 students had been trained compared to $67 \%-81 \%$ of $\mathrm{P} 2$, P3, and P4 students. Fifty-seven percent of participants felt prepared to administer naloxone and $46 \%$ had dispensed it. Most common sources of the opioid crisis mentioned were school curriculum, places of employment, media, and personal experience.

\section{DISCUSSION}

Inappropriate prescribing by prescribers was the most often mentioned cause of the opioid crisis. Inappropriate prescribing leading to widespread availability and misuse of opioids is implicated in the literature as a major cause of the opioid crisis, with many factors contributing to high rates of prescription opioid use and misuse. ${ }^{6}$ Physician-prescribing practices play an important role as evidence suggests that more than $30 \%$ of opioid misuse is associated with patients with prescription opioids. ${ }^{7,8}$ Inappropriate opioid prescribing, defined as inadequate, continued, or excessive, poses high risks of causing patient morbidity and mortality. ${ }^{9-11}$ Prescribers were mentioned as succumbing to pressures from short appointment times and fears of pain undertreatment. We theorize a general lack of awareness about the safe use of opioids, abuse, addiction, and overdose potential for chronic users can apply to prescribers, patients, health care professionals, and the public. Mentions were not specific regarding those who lacked awareness as a cause of the crisis.

Participants believed that patients who were not educated about how to use the medication appropriately did not understand the addiction potential and risks of longterm use. The crisis is exacerbated by opioid use disorder (OUD), which has been described with patient behaviors including use of multiple pharmacies and providers to obtain opioids (termed "doctor-pharmacy shopping"), cash payments to avoid insurance restrictions, and use of friends, relatives, or a black-market supplier. ${ }^{12} \mathrm{~A}$ few students believed socioeconomic factors were contributory, which, from a public health perspective, is a root cause of addiction at the population level. ${ }^{13}$ While the scope of this study did not specifically aim to assess pharmacy student knowledge on the role of social determinants of health (SDoH) in the opioid crisis, we were surprised that so few students identified psychosocial and socioeconomic factors as an underlying cause of the opioid crisis, when the literature is clear regarding the impact of those factors. ${ }^{14}$ Research has shown that the deep roots of the opioid crisis in social and economic determinants, with some analyses focusing on "diseases of despair," in referring to the interconnected trends in fatal drug overdose, suicide, and alcohol-related disease. ${ }^{14-17}$ Students' lack of perspective is notable given that most academic institutions focus on $\mathrm{SDoH}$ within their curriculum and may indicate that pharmacists share the same lack of recognition; this phenomenon would likely contribute to the stigma toward patients with OUD. ${ }^{18}$

Opioid manufacturers have faced lawsuits citing their responsibility in the crisis. The pharmaceutical industry has been implicated as a contributing factor to the opioid crisis because of their incentives to prescribers, false advertising, and aggressive product marketing without disclosing the addictive nature of the products. ${ }^{19,20}$

Pharmacists who do not provide adequate counseling, education, monitoring, or had personal misconceptions regarding opioid were mentioned as a cause of the crisis. Pharmacists play an important role in protecting public 


\section{American Journal of Pharmaceutical Education 2021; 85 (7) Article 8515.}

Table 2. Pharmacy Students' Mentions of Key Topics and Terms Regarding the Opioid Crisis During Focus Groups ${ }^{\mathrm{a}}$

Table 2. Pharmacy Students' Mentions of Key Topics and Terms Regarding the Opioid Crisis During Focus Groups a

Domains and Subdomain (brief description)

Mentions

\section{Causes of the crisis}

Prescriber [appointment too short, malpractice, overprescribing (duration or quantity), lack of pharmacology experience, misconceptions, misunderstanding of physiology of addiction, prescriber fears (under/over treatment, challenge other prescribers, high dose opioids etc.)]

Lack of awareness (overdose)

Patient (doctor shopping, misunderstanding of physiology/psychology/chemistry of addiction, not understanding addictive nature of some drugs, misconceptions that prescription drugs are safe, lack of education)

Industry/manufacturer (false advertisement/prescriber incentives/drug development)

Pharmacist (inadequate counseling/patient education, misconceptions, lack of monitoring)

Pain is subjective (different types of pain with different diagnosis code: cancer, chronic, terminal)

Accessibility to opioids (opioids versus street drugs)

Corporate policies (short-staffed, discourage counseling)

Patient population (young patient: sports/injuries; socioeconomic: homeless; elderly patient:

arthritis)

FDA regulations/guidelines (clearer guideline/steps in therapy/reduce prescribing frequency)

Cultural influence (music about drugs, other cultural influences)

\section{Overall impact of the crisis}

Deaths

Overdoses that don't result in death

Stigma contributing to the crisis

Patient attitude contributing to later stigma by pharmacy staff (frustration/aggressive/argumentative/

urgency/emotional)

Public perspectives (addiction as a choice versus an illness)

$\mathrm{PMH} /$ medication history (medication for addiction/controlled substances/other opioids)

Early fills/due date as a trigger for suspicion

Stigma toward needle users/injectables (needles/syringe uses versus drug addict, transition to illicit drug use)

Judgements based on patients' appearance (age, the way they dressed, nails, teeth, etc.)

Bias against certain prescribers/clinics (negative experiences with healthcare system, etc.)

Large quantities/high dose of opioids

Healthcare professional's perspectives (addiction as a choice versus illness)

6

Payment method (cash pay, no insurance, etc.)

Socioeconomic status (stereotyping)

Relationship w/ pharmacist (eg, new patient)

Geography (eg, out-of-state, rural area. travel far)

Prescription (hard copy, marked with different color pen)

\section{Solutions to the opioid crisis}

Pharmacy practice solutions [double check prescription, PDMP, argument, increased communication

(eg, doctor calls), patient contracts (normally with pain clinics), legislative guidance (follow law/ policy), policy reform (harm reduction policy, opioid policy, laws etc.), clinical guidance (treatment guidelines, etc.), commercial/advertisements warnings (FDA, manufacturers)]

Therapeutic solutions (alternative therapies, drug therapy (NSAIDS, injections, APAP, opioid tapers, etc.), non-drug therapy (chiropractor, acupuncture, etc.), addiction or mental health counseling) 


\section{American Journal of Pharmaceutical Education 2021; 85 (7) Article 8515.}

Table 2. (Continued)

\section{Domains and Subdomain (brief description)}

Mentions

Healthcare system solutions (adding specialists to the team; assisting patients with addiction;

(N)

awareness (provider, community etc.); patient empowerment; continuing research (companies);

commercial warnings)

\section{Education}

Student education [increased lecture opportunities (guest speakers, class lectures); increased

situational experiences (skills lab to identify/handle overdose); provide naloxone training; increased

exposure (student organizations, health fairs, earlier in curriculum)]

Patient education: increase counseling by prescribers/pharmacists; pharmacists' counseling [warning

stickers, drug/naloxone counseling; increase community awareness (community workshops)]

Healthcare professionals' education (pharmacists; medication counseling, increased education,

adequate education; prescribers: need for pharmacology)

Education to reduce stigma (opioid use can be good and bad; normalize naloxone (to public, healthcare professional, increase access etc.), addiction can be environmental, addiction can be destigmatized)

\section{Naloxone}

Availability (case by case basis; public spaces (hotels, apartments, near fire extinguishers/AEDs);

community spaces (law enforcement, schools); those with children/elderly in the household)

Awareness (family members, healthcare professionals)

Sources

School/curriculum (research, classes, projects, naloxone training, rotation)

Pharmacy (community, inpatient, ambulatory, other)

Media (news, drug company trials, advertisements)

Personal [community, social media, overdose (friends/family)]

Professional organizations (student organizations, CDC, clinics, magazines, naloxone training)

Lack of resources as a barrier (mental health support, individualized therapy, med disposal)

Professional (EMT, online training, CE for pharm tech, drug rehabilitation center)

Others (drug court, police)

Healthcare providers (prescribers, pharmacists)

a This study recruited first through fourth year Doctor of Pharmacy students from eight US schools and colleges: Binghamton University, Butler University, Creighton University, University of Michigan, University of Minnesota-Duluth, Midwestern University-Chicago, Purdue University, and St. Louis College of Pharmacy. The number and ranking of participants from each school varied.

Abbreviations: $\mathrm{PMH}=$ past medical history, $\mathrm{PDMP}=$ Prescription Drug Monitoring Program, FDA $=$ Food \& Drug Administration, $\mathrm{NSAIDS}=$ nonsteroidal anti-inflammatory drugs, $\mathrm{APAP}=$ acetaminophen, $\mathrm{AED}=$ automatic external defibrillator, $\mathrm{CDC}=\mathrm{Centers}$ for $\mathrm{Disease}$ Control, EMT $=$ emergency medical technician, $\mathrm{CE}=$ continuing education.

health and safety. ${ }^{21}$ The Centers for Disease Control (CDC) reported that $25 \%-66 \%$ of fatal opioid overdoses occurred after using another patient's prescription medication. $^{22}$ National Survey on Drug Use and Health (NSDUH) data indicates that more than $30 \%$ of opioid misuse is from patients who were prescribed opioids. Pharmacists are responsible for providing education and counseling and monitoring patients using opioids to affect this cause.

Two subdomains, deaths and overdoses that do not result in death, were mentioned only 13 times, which was unexpected given the significance of the overall impact of the crisis to public health. The opioid epidemic has not been associated with an increase in violent or property crime; however, students recognized that as a patient's access to prescription opioids dwindles, they often try to obtain cheaper, illicit drugs. ${ }^{23}$ No mentions were made of the significant emotional, economic, and quality of life burdens that patients and their families experience related to the opioid crisis. ${ }^{24}$

Participants mentioned that stigma focused on negative perceptions of substance use disorder (SUD) and was palpable as evidenced by attitudes and practices within the pharmacy setting. Some pharmacy staff were openly 
American Journal of Pharmaceutical Education 2021; 85 (7) Article 8515.

Table 3. Pharmacy Student Responses to Quantitative Questions Regarding the Opioid Crisis and Use of Naloxone ${ }^{\text {a }}$

\begin{tabular}{|c|c|c|c|c|c|c|c|c|c|c|}
\hline Quantitative Question & $\begin{array}{c}\text { P1 } \\
\text { Yes/Total } \\
(\mathbf{N}) \\
\end{array}$ & $\begin{array}{l}\text { P1 } \\
\text { Yes } \\
(\%)\end{array}$ & $\begin{array}{c}\text { P2 } \\
\text { Yes/Total } \\
(\mathbf{N}) \\
\end{array}$ & $\begin{array}{l}\text { P2 } \\
\text { Yes } \\
(\%) \\
\end{array}$ & $\begin{array}{c}\text { P3 } \\
\text { Yes/Total } \\
(\mathbf{N}) \\
\end{array}$ & $\begin{array}{l}\text { P3 } \\
\text { Yes } \\
(\%) \\
\end{array}$ & $\begin{array}{c}\text { P4 } \\
\text { Yes/Total } \\
\text { (N) }\end{array}$ & $\begin{array}{l}\text { P4 } \\
\text { Yes } \\
(\%) \\
\end{array}$ & \multicolumn{2}{|c|}{ All Grade Levels } \\
\hline $\begin{array}{l}\text { Is there a crisis with } \\
\text { opioids? }\end{array}$ & $48 / 48$ & 100 & $30 / 31$ & 97 & $35 / 36$ & 97 & $34 / 34$ & 100 & $147 / 149$ & 99 \\
\hline $\begin{array}{l}\text { Is there a stigma or bias } \\
\text { from the pharmacy } \\
\text { community about } \\
\text { opioid use? }\end{array}$ & $40 / 49$ & 82 & $30 / 31$ & 97 & $36 / 36$ & 100 & $33 / 34$ & 97 & $139 / 150$ & 93 \\
\hline $\begin{array}{c}\text { How many of you have } \\
\text { dispensed naloxone? }\end{array}$ & $13 / 49$ & 27 & $19 / 31$ & 61 & $14 / 36$ & 39 & $23 / 34$ & 68 & $69 / 150$ & 46 \\
\hline $\begin{array}{l}\text { How many of you have } \\
\text { witnessed the } \\
\text { administration or use of } \\
\text { naloxone? }\end{array}$ & $7 / 49$ & 14 & $5 / 31$ & 16 & $6 / 36$ & 17 & $5 / 34$ & 15 & $23 / 150$ & 15 \\
\hline $\begin{array}{l}\text { How many of you feel } \\
\text { you are prepared to } \\
\text { administer naloxone if } \\
\text { the need arises? }\end{array}$ & $17 / 49$ & 35 & $15 / 31$ & 48 & $25 / 36$ & 69 & $28 / 34$ & 82 & $85 / 150$ & 57 \\
\hline $\begin{array}{l}\text { How many of you carry } \\
\text { naloxone? }\end{array}$ & $6 / 47$ & 13 & $6 / 31$ & 19 & $6 / 36$ & 17 & $5 / 34$ & 15 & $23 / 148$ & 16 \\
\hline $\begin{array}{l}\text { How many of you have } \\
\text { administered naloxone } \\
\text { to someone? }\end{array}$ & $0 / 49$ & 0 & $3 / 31$ & 10 & $0 / 36$ & 0 & $1 / 34$ & 3 & $4 / 150$ & 3 \\
\hline
\end{tabular}

a This study recruited first through fourth year Doctor of Pharmacy students from eight US schools and colleges: Binghamton University, Butler University, Creighton University, University of Michigan, University of Minnesota-Duluth, Midwestern University-Chicago, Purdue University, and St. Louis College of Pharmacy. The number and ranking of participants from each school varied.

biased against certain prescribers and clinics that served individuals with SUD and against patients who received high doses of opioids and/or medications for treating OUD. Research indicates that negative attitudes of health professionals toward patients with SUD are common and contribute to suboptimal health care for these patients. ${ }^{25-27}$ A systematic review by Van Boekel and colleagues indicated that health care providers lacked proper education on how to best care for individuals with SUD, and there was less provider involvement, more task-oriented approaches, and decreased personal interaction with these patients. ${ }^{25}$ Stigma toward individuals who received drugs from health care professionals and systems resulted in decreased utilization of services. ${ }^{27}$ Participants mentioned that some pharmacy staff believed that addiction is a choice rather than a medical illness. There appeared to be a culture in which pharmacy staff were on high alert for potential signs of misuse of opioids, including early refills, large quantities and/or high doses, cash payments, and signs of altered prescriptions. Some participants believed that these practices crossed a line, passing beyond vigilance into bias.

When discussing stigma directed toward patients, multiple patient-related factors that contribute to the opioid crisis were mentioned. Negative emotions (eg, frustration and aggression) and behaviors (eg, argumentative and 


\section{American Journal of Pharmaceutical Education 2021; 85 (7) Article 8515.}

emotional) can lead to a higher perceived level of danger. ${ }^{25}$ Public perspectives focused on addiction as a choice vs an illness is frequently highlighted in literature as a significant contributing factor to the opioid crisis. ${ }^{6,28-30}$ Stigma surrounding needle use was mentioned. Nora Volkow, Director of the National Institute on Drug Abuse (NIDA), noted that those who use injectable drugs are sometimes denied care in hospital settings because they are viewed as drug seeking. ${ }^{6}$ Physical appearance (eg, age, attire, and/or the condition of nails or teeth) and socioeconomic status impacting stigma was mentioned less frequently by participants. McGinty and Barry showed that negative attitudes related to addiction are very closely linked to stigma against some socioeconomic classes and races. ${ }^{29}$ Patients' geographic variables (eg, out of state, rural areas, and distance traveled) and depth of a patient-pharmacist relationship were also mentioned as impacting stigma.

Change requires community participation in learning solutions, improved management of care, and more consistent use of better pain-control options. ${ }^{31}$ Overcoming the crisis will involve critical evidenced-based methods that address research, clinical, and educational apprehensions. ${ }^{31}$ Participants shared perspectives on multifactorial solutions to stop the opioid crisis. Prescription drug monitoring programs (PDMPs) along with pharmacists rechecking prescriptions, increasing communication among other health care providers, applying patient contracts in pharmacies similar to those used in pain clinics, and following policies and procedures implemented by the law were mentioned as solutions to combat the opioid crisis.

Participants discussed using the US Centers for Disease Control and Prevention (CDC) guidelines as an educational tool. Skolnick reported that informing society about CDC prescribing guidelines was a strategy within pharmacy practices. $^{32}$ Guideline recommendations include finding alternative pain therapies, using nonsteroidal anti-inflammatory drugs, acetaminophen, nonpharmacological therapy, and/or having patients attend addiction or mental counseling. Additionally, understanding the basis of pain can help eradicate the opioid crisis. ${ }^{32}$ Health care systems could implement strategies to tackle the opioid crisis by adding addiction specialists to the health care team to assist patients with SUD treatment, continuing research, and applying commercial warnings about use to prevent OUD. Responses to the opioid crisis should address inadequate resources, societal ills that promote addiction, and stigma that is attached to illicit drug use. ${ }^{31}$

Pharmacists can prevent opioid-related deaths by dispensing naloxone and educating patients and family members on how to use it; however, many community pharmacists do not feel comfortable doing so. ${ }^{33,34}$ The data presented here indicate that opioid-related education for health care providers is needed, including training pharmacists in counseling patients about naloxone use as well as pharmacist- and prescriber-focused education to reduce stigma. The ability for education to reduce stigma has been well described in the literature. ${ }^{6,28,29}$

While there are a number of programs focused on the opioid crisis for health care professionals and community members, the quality of the training is highly variable. ${ }^{35}$ Most naloxone training programs discuss essential clinical topics including administration, formulation, and adverse events. ${ }^{36,37}$ Additional education could include pharmacistpatient and pharmacist-caregiver communication to increase confidence and effectiveness. ${ }^{37}$

Many participants in focus groups had community pharmacy experience and exposure to expanded naloxone access laws across many states that grants pharmacists direct or indirect authority to dispense naloxone with autonomy, often times without a prescription. ${ }^{38}$ While $46 \%$ of participants reported having dispensed naloxone, only $15 \%$ had witnessed administration or use of naloxone. For those who had seen an opioid reversal, they reported improved acceptance of naloxone after seeing the ease of use and immediacy of response. Significant reductions in opioid overdose deaths have been linked to states with laws which allow pharmacist direct authority to dispense naloxone without a prescription, yet $31 \%$ of participants reported making this recommendation to patients during their training. ${ }^{39}$

Naloxone education should ensure that students can identify who would benefit from naloxone, such as patients with risk factors for respiratory depression from opioids, regardless of whether they have a prescription. Improving students' knowledge of naloxone during their pharmacy education can support the success of expanded naloxone access laws, although more pharmacy schools are starting to report naloxone education as part of their curriculum, the breadth and depth of the training varies greatly. ${ }^{40-44}$ Sixty-four percent of participants in focus groups had received some training on naloxone and 57\% reported feeling prepared to administer naloxone. Based on these numbers, increased formal training to administer naloxone should increase student pharmacists' confidence level. Despite common knowledge of opioid overdoses occurring in public community spaces, only $16 \%$ of students carried naloxone themselves and only $3 \%$ had ever administered naloxone.

Greater awareness and availability to promote naloxone access were two predominant themes mentioned by participants. Health care professionals and family members of individuals who use opioids would benefit from improved awareness. Although naloxone education by 


\section{American Journal of Pharmaceutical Education 2021; 85 (7) Article 8515.}

harm reduction organizations targeted at people with OUD has been successful, stigma with naloxone arguably makes counseling more difficult with people who are prescribed opioids for acute or chronic pain. ${ }^{35}$ Pharmacy student education should incorporate the nuances of counseling patients on opioid overdose prevention by embracing non-stigmatizing language with an emphasis on specific health factors, such as substance use disorders or respiratory disease, that pose additional respiratory risks to the patient when using opioids. Conversations with patients can be more compelling to address the dangers of inadvertent opioid administration to other people and pets in their home. ${ }^{45}$

Participants reported being in favor of increased access to naloxone in public spaces, such as schools, hotels, and airports, and in conjunction with automated external defibrillators. Education should include that, while naloxone can immediately restore breathing in someone whose respiratory drive is impaired by opioids, it is harmless if administered to a person without opioids in their system. This knowledge prepares students to address common concerns with public access, such as fear of causing harm by administering naloxone and/or having any personal liability for the person's outcome. Students should also be aware of Good Samaritan laws in their states, which provide criminal and civil immunity to anyone administering naloxone to reverse an overdose.

Pharmacy students foster common stigmas associated with naloxone, despite recognizing its benefits. Some reported that access to naloxone encourages opioid misuse, which has repeatedly been proven false by research. ${ }^{46,47}$ Without professional training, pharmacy students are prone to the perpetuation of the public's misconceptions and stigma for naloxone. Participants mentioned that naloxone was rarely discussed among their peers or professors and noted that they had not seen any advertisements regarding naloxone from the media.

Seventy-four percent of participants agreed with the CDC's recommendations for co-prescribing naloxone and opioids. ${ }^{48}$ Several participants mentioned that more primary care providers should counsel patients on naloxone and believed first responders should leave naloxone with people revived from an overdose.

The financial burden of naloxone was a common concern reported by participants. Pharmacy students must appreciate the value of carrying naloxone and be able to make recommendations for different formulations if cost is a barrier for the patient.

Participants described receiving naloxone education in the curricula spanning all educational formats, including lecture, school projects, rotations, student, and professional organizations. First-year students primarily received knowledge from family, friends, and media sources, while P2-P4 students reported learning about naloxone from coursework. Independent of source, students consistently believed that their exposure to naloxone use was positive and beneficial.

When asked to provide sources that have impacted views on or awareness of the opioid crisis, the most mentioned subdomains were school/curriculum, pharmacy experiences, media, and personal experiences. While participants discussed answers to the specific question, sources were mentioned in responses to other focus group questions.

Doctor of pharmacy programs are accredited by the Accreditation Council for Pharmacy Education and often look to professional organizations, including AACP, for guidance related to substance use curricula. ${ }^{18}$ Curricula including introductory and advanced pharmacy practice experiences help shape future pharmacists' professional approach to patient care. Many students are employed in pharmacy settings as interns and technicians. Practicing pharmacists mentor students and are often role models on rotations and when interacting with various patient populations and other health professionals. Whether in class or completing practice experience, students are exposed to opioid pharmacotherapy and prescription dispensing. Students may be introduced to national and community issues including substance use disorders and public health initiatives during courses and experiences. Therefore, it was not surprising to the authors that professional programs and pharmacy experience were identified as most impactful to student perspectives about the opioid crisis. There may have been unconscious bias to discussion about the impact of professional training as focus groups were conducted by pharmacy faculty and researchers.

Specific media sources included clinical trials, news, and advertisements. However, access or frequency of access to media was not determined from the focus group discussions. Information about the opioid crisis is evident in mass media, and drug discovery to treat opiate misuse and overdose is evolving. Drug court and police were mentioned in response to the media source question; however, it was not determined whether participants had personal experience with court-based programs or police. When reflecting about the opioid crisis, the students' perspectives were more in line with those of health professionals than those of judicial and department of correction professionals. Personal experiences included overdose events that occurred within their community, were reported on social media, and/or involved family or friends. Some participants may not have felt comfortable sharing personal experiences.

This study has some limitations. Our research involved several academic institutions and a large number 


\section{American Journal of Pharmaceutical Education 2021; 85 (7) Article 8515.}

of focus groups; thus, inconsistencies between institutions in how focus groups were created and conducted may have occurred and influenced study results. More P1 students (32.7\%) participated than P2, P3, or P4 students, and their perspectives were likely different from those of upperclassmen who had more experience in pharmacy school. We initially had planned to have a purposive sample with a similar number of students in each focus group. However, because focus group participation was voluntary and no incentives were offered, we were unable to achieve this goal. Sample size at each school varied, resulting in a convenience sample, which may limit the applicability of the study findings to the general population of pharmacy students.

Although the focus group questions were vetted by faculty educators, they were broad and open-ended, which introduced an additional limitation to this study. The time restraints (1-1.5 hours) of the focus groups and the broad research questions did not allow the moderator to ask more focused questions to address the deeper causes of the opioid crisis. Additionally, focus group sizes varied and smaller groups tended to finish faster. While participants were given unlimited time to speak and respond to questions, some students may have perceived insufficient time or felt uncomfortable to thoroughly express their viewpoints.

One clear limitation of this study was a focus on the "supply" perspective of the opioid epidemic, contemporary pharmacy practice, and pharmacist/student attitudes toward individuals with OUD rather than the "demand" perspective, which would be more helpful in a public health context. For example, we noted that few participants identified psychosocial and socioeconomic factors as an underlying cause of the opioid crisis. Further research is needed to determine whether this was because of the study design and questioning route or if participants were simply unaware of the deep impact of social and economic factors on the opioid crisis. Pharmacy students and pharmacists cannot effectively address the opioid crisis if causes and impacts of substance use disorders related to individual patients are not well understood, and this is a potentially critical area in which the Academy needs to provide guidance.

Finally, while the student coders were trained in conducting CQR analysis, not all of them had previous experience in this methodology. The student coders' lack of experience in qualitative research methods may have influenced our study results, despite the meetings and support provided throughout the CQR process. While student coders and faculty auditors completed a bias self-check prior to coding, there is always the potential that life experiences and positive or negative biases could have impacted the coding process, even though adherence to the CQR methodology minimizes this phenomenon.

\section{CONCLUSION}

Education and curriculum were frequently mentioned by pharmacy students under multiple domains, reaffirming the importance of guidance for schools from organizations such as AACP in SUD/OUD. ${ }^{18}$ Pharmacists and pharmacy schools could benefit from our results, including recognition of how stigma and bias contribute to poor health outcomes for individuals with SUD/OUD and the concerning lack of acknowledgement by pharmacy students of the social determinants of health impacting the opioid crisis. This study documents what student pharmacists are learning about the opioid crisis, practices they are seeing, and belief sets that influence pharmacy experiences. Results provide information needed to develop ideas and recommendations to address the crisis in pharmacy education. We believe that the Academy must leverage its uniquely strategic position to guide pharmacist educators in curricula that stress the critical role of social determinants of health in substance use and strive to educate students on the ways that bias and stigma interfere with patient care. As a profession, we must do better to do no harm.

In our analysis of the quantitative data, an association between students' perspectives and their year in pharmacy school began to emerge. We plan to analyze the qualitative information by year in school, further examine the results and perspectives compared to programmatic sequences of curricula and make specific recommendations for improvement to each program. A few of the programs involved in this study have already made curricular adaptations based on our results.

\section{ACKNOWLEDGMENTS}

We gratefully acknowledge the thorough and thoughtful work of students who participated in the rigorous coding process (Minnesota-Duluth): Ashley Dahley, Lucas Kosobuski, Mikaela Leifeld, Tuyen Nguyen, and Sarah Zahirudin, and from Purdue: Aisha Ansar, Wan Ying Cheng, Geoffrey Pucci, and Zerong Qiu. Special thanks also to the students who served in a research assistant capacity, Jessica Raines (Minnesota-Duluth) and Laura Tonner (Butler).

\section{REFERENCES}

1. U.S. Department of Health and Human Services. HHS acting secretary declares public health emergency to address national opioid crisis. Released October 26, 2017. https://public3.pagefreezer.com/ browse/HHS.gov/31-12-2020T08:51/ https://www.hhs.gov/about/ 


\section{American Journal of Pharmaceutical Education 2021; 85 (7) Article 8515.}

news/2017/10/26/hhs-acting-secretary-declares-public-healthemergency-address-national-opioid-crisis.html. Accessed August 9, 2021.

2. Centers for Disease Control and Prevention. Understanding the epidemic. three waves of opioid overdose deaths. https://www.cdc. gov/opioids/basics/epidemic.html. Accessed August 9, 2021.

3. Guy GP Jr, Zhang K, Bohm MK, et al. Vital signs: change in opioid prescribing in the United States, 2006-2015. MMWR Morb Mortal Wkly Rep. 2017;66:697-704.

4. Centers for Disease Control and Prevention. Drug and opioidinvolved overdose deaths - United States, 2017-2018. Morbidity and Mortality Weekly Report. https://www.cdc.gov/mmwr/volumes/69/ wr/mm6911a4.htm?s_cid=mm6911a4_w. Accessed August 9, 2021. 5. Hill CE, Knox S, Thompson BJ, Williams EN, Hess SA, Ladany N. Consensual qualitative research: an update. J Couns Psychol. 2005;52(2):196-205. doi:10.1037/0022-0167.52.2.196.

6. Volkow ND, Jones EB, Einstein EB, Wargo EM. Prevention and treatment of opioid misuse and addiction: a review. JAMA Psych. 2019; 76(2):208-16. doi.org/10.1001/jamapsychiatry.2018.3126.

7. Kim B, Nolan S, Beaulieu T, et al. Inappropriate opioid prescribing practices: a narrative review. Am J Health-Syst Pharm. 2019;76: 1231-1237. doi.org/10.1093/ajhp/zxz092.

8. Compton WM, Jones CM, Baldwin GT. Nonmedical prescription opioid use and heroin use. N Engl J Med. 2016;374(13):1296.

9. Shei A, Rice JB, Kirson NY, et al. Sources of prescription opioids among diagnosed opioid abusers. Curr Med Res Opin. 2015;31(4): 779-784. doi.org/10.1185/03007995.2015.1016607.

10. Dhalla IA, Persaud N, Juurlink DN. Facing up to the prescription opioid crisis. BMJ. 2011;343:d5142. doi.org/10.1136/bmj.d5142. 11. Liu Y, Logan JE, Paulozzi LJ, et al. Potential misuse and inappropriate prescription practices involving opioid analgesics. Am J Manag Care. 2013;19(8):648-658.

12. Logan J, Liu Y, Paulozzi L, et al. Opioid prescribing in emergency departments: the prevalence of potentially inappropriate prescribing and misuse. Med Care. 2013;51(8):646-653. doi.org/10. 1097/MLR.0b013e318293c2c0.

13. Rickles NM, Huang AL, Gunther MB, Chan WJ. An opioid dispensing and misuse prevention algorithm for community pharmacy practice. Res Soc Adm Pharm. 2019;15(8):959-965. doi.org/10.1016/ j.sapharm.2018.02.004.

14. Fraser M, Plescia M. The opioid epidemic's prevention problem. Am J Public Health. 2019;109(2):215-217. doi.org/10.2105/AJPH. 2018.304859.

15. Dasgupta N, Beletsky L, Ciccarone D. Opioid crisis: no easy fix to its social and economic determinants. Am J Public Health. 2018; 108(2):182-186. doi.org/ 10.2105/AJPH.2017.304187

16. Barocas JA, Wang J, Marshall BDL, et al. Sociodemographic factors and social determinants associated with toxicology confirmed polysubstance opioid-related deaths. Drug Alcohol Depend. 2019; 200:59-63. doi.org/10.1016/j.drugalcdep.2019.03.014

17. Case A, Deaton A. Mortality and morbidity in the 21 st century. https://www.brookings.edu/wp-content/uploads/2017/03/6_ casedeaton.pdf. Accessed August 9, 2021.

18. Stein EM, Gennuso KP, Ugboaja DC, Remington PL. The epidemic of despair among White Americans: trends in the leading causes of premature death, 1999-2015. Am J Public Health. 2017; 107(10):1541-1547.

19. Tran T, Ball J, Bratberg JP, et al. Report of the 2020 Special Committee on Substance Use and Pharmacy Education. Am J Pharm Educ. 2020;84(11):8421. doi.org/10.5688/ajpe8421.
20. Hadland SE, Cerda M, Li Y, et al. Association of pharmaceutical industry marketing of opioid products to physicians with subsequent opioid prescribing. JAMA Intern Med. 2018;178(6):861-863. doi.org/ 10.1001/jamainternmed.2018.1999.

21. Van Zee A. The promotion and marketing of oxycontin: commercial triumph, public health tragedy. Am J Public Health. 2009;99: 221-227. doi.org/10.2105/AJPH.2007.131714.

22. Pringle JL, Cochran J, Aruru M. Role of pharmacists in the Opioid Use Disorder (OUD) crisis. Res Soc Adm Pharm. 2019;15(2): 228-229. doi.org/10.1016/j.sapharm.2018.11.005.

23. Centers for Disease Control and Prevention (CDC). CDC grand rounds: prescription drug overdoses - a U.S. epidemic. MMWR Morb Mortal Wkly Rep. 2012;61(1):10-13. http://www.ncbi.nlm.nih.gov/ pubmed/22237030. Accessed August 9, 2021.

24. Szalavitz M, Rigg KK. The curious (dis)connection between the opioid epidemic and crime. Substance Use \& Misuse. 2017;52(14): 1927-1931. doi.org/10.1080/10826084.2017.1376685.

25. Hagemeier NE. Introduction to the opioid epidemic: the economic burden on the healthcare system and impact on quality of life. Am J Manag Care. 2018;24:S200-S206.

26. van Boekel LC, Brouwers EPM, van Weeghel J, Garretsen HFL. Stigma among health professionals towards patients with substance use disorders and its consequences for healthcare delivery: systematic review. Drug Alcohol Depend. 2013;131(1-2):23-35. doi.org/10. 1016/j.drugalcdep.2013.02.018.

27. Garretsen HFL. Stigma among health professionals towards patients with substance use disorders and its consequences for healthcare delivery: systematic review. Drug Alcohol Depend. 2013;131(12):23-35. doi.org/10.1016/j.drugalcdep.2013.02.018

28. Paquette CE, Syvertsen JL, Pollini RA. Stigma at every turn: health services experiences among people who inject drugs. Int $J$ Drug Policy. 2018 Jul;57:104-110. doi.org/10.1016/j.drugpo.2018. 04.004.

29. Tsai AC, Kiang MV, Barnett ML, et al. Stigma as a fundamental hindrance to the United States opioid overdose crisis response. PLoS Medicine. 2019;16(11):e1002969. doi.org/10.1371/journal.pmed. 1002969.

30. McGinty E, Barry C. Stigma reduction to combat the addiction crisis - developing an evidence base. NEng J Med. 2020;382(14): 1291-1292. doi.org/10.1056/NEJMp2000227.

31. Corrigan PW, Nieweglowski K. Stigma and the public health agenda for the opioid crisis in America. Int J Drug Policy. 2018;59: 44-49. doi.org/10.1016/j.drugpo.2018.06.015.

32. McIver JS. Seeking solutions to the opioid crisis. $P$ T. 2017; 42(7):478.

33. Skolnick P. The opioid epidemic: crisis and solutions. Annu Rev Pharmacol Toxicol. 2018;6(58):143-159. doi.org/10.1146/annurevpharmtox-010617-052534.

34. Thornton JD, Lyvers E, Scott VGG, Dwibedi N. Pharmacists' readiness to provide naloxone in community pharmacies in West Virginia. J Am Pharm Assoc. 2017;57(2):S12-S18 e14.

35. Nielsen S, Menon N, Larney S, Farrell M, Degenhardt L. Community pharmacist knowledge, attitudes and confidence regarding naloxone for overdose reversal. Addiction. 2016;111(12):2177-2186. 36. Wheeler E, Jones TS, Gilbert MK, Davidson PJ. Opioid overdose prevention programs providing naloxone to laypersons - United States, 2014. MMWR Morb Mortal Wkly Rep. 2015;64(23):631-635. https://www.researchgate.net/publication/278731280_Opioid_ Overdose_Prevention_Programs_Providing_Naloxone_to_ Laypersons_-_United_States_2014. Accessed August 9, 2021. 


\section{American Journal of Pharmaceutical Education 2021; 85 (7) Article 8515.}

37. Bailey AM, Wermeling DP. Naloxone for opioid overdose prevention: pharmacists' role in community-based practice settings. Ann Pharmacother. 2014;48(5):601-606.

38. Carpenter DM, Roberts CA, Westrick SC, et al. A content review of online naloxone continuing education courses for pharmacists in states with standing orders. Res Social Adm Pharm. 2018 Oct;14(10):968-978. doi.org/10.1016/j.sapharm.2017.11.011. 39. Roberts AW, Carpenter DM, Smith A, Look KA. Reviewing state-mandated training requirements for naloxone-dispensing pharmacists. Res Social Adm Pharm. 2019;15(2):222-225. doi.org/10. 1016/j.sapharm.2018.04.002.

40. Abouk R, Pacula RL, Powell D. Association between state laws facilitating pharmacy distribution of naloxone and risk of fatal overdose. JAMA Intern Med. 2019;179(6):805-811. doi.org/10.1001/ jamainternmed.2019.0272.

41. Kwon M, Moody AE, Thigpen J, Gauld A. Implementation of an opioid overdose and naloxone distribution training in a pharmacist laboratory course. Am J Pharm Educ. 2020;84(2):7179.

42. Schartel A, Lardieri A, Mattingly A, Feemster A. Implementation and assessment of a naloxone-training program for first-year student pharmacists. Curr Pharm Teach Learn. 2018;10(6):717-722. doi.org/10.1016/j.cptl.2018.03.016.

43. Jacobson AN, Bratberg JP, Monk M, Ferrentino J. Retention of student pharmacists' knowledge and skills regarding overdose management with naloxone. Subst Abus. 2018;39(2):193-198. doi.org/10. 1080/08897077.2018.1439797.
44. Hill LG, Sanchez JP, Laguado SA, Lawson KA. Operation naloxone: overdose prevention service learning for student pharmacists. Curr Pharm Teach Learn. 2018;10(10):1348-1353. doi.org/10.1016/ j.cptl.2018.07.010.

45. Bachyrycz A, Takeda MY, Wittstrom K, Bleske B. Opioid overdose response training in pharmacy education: an analysis of students' perception of naloxone use for opioid overdose prevention. Curr Pharm Teach Learn. 2019;(2):166-171. doi.org/10.1016/j.cptl. 2018.11.007.

46. Khan NF, Bateman BT, Landon JE, Gagne JJ. Association of opioid overdose with opioid prescriptions to family members. JAMA Intern Med. 2019;179(9):1186-1192. doi.org/10.1001/ jamainternmed.2019.1064.

47. Maxwell S, Bigg D, Stanczykiewicz K, Carlberg-Racich S. Prescribing naloxone to actively injecting heroin users: a program to reduce heroin overdose deaths. J Addict Dis. 2006;25(3):89-96. doi. org/10.1300/J069v25n03_11. PMID: 16956873.

48. Wagner KD, Valente TW, Casanova M, et al. Evaluation of an overdose prevention and response training programme for injection drug users in the Skid Row area of Los Angeles, CA. Int J Drug Policy. 2010 May;21(3):186-193. doi.org/10.1016/j.drugpo.2009.01. 003.

49. Centers for Disease Control and Prevention. CDC guideline for prescribing opioids for chronic pain - United States, 2016. https:// www.cdc.gov/mmwr/volumes/65/rr/rr6501e1.htm\#recommendations. Accessed August 9, 2021. 